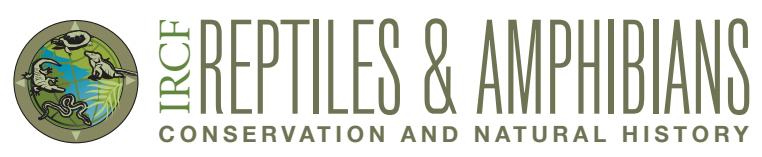

\title{
Morphology and Natural History of Three- lined Snakes, Atractus trilineatus (Squamata, Dipsadidae), in the Eastern Caribbean
}

\author{
John C. Murphy ${ }^{1}$, Daniele Salvi ${ }^{2}$, Alvin L. Braswell ${ }^{3}$, and Michael J. Jowers ${ }^{4}$ \\ ${ }^{1}$ Science and Education, Field Museum, 1400 S. Lake Shore Drive, Chicago, Illinois 60605, USA; \\ Current address: 2564 E. Murdoch Ct., Green Valley, Arizona 85614, USA (serpentresearch@gmail.com) \\ ${ }^{2}$ Department of Health, Life, and Environmental Sciences, University of L'Aquila, Via Vetoio snc, 67100 L'Aquila-Coppito, Italy \\ ${ }^{3}$ North Carolina State Museum of Natural Sciences, 11 West Jones Street, Raleigh, North Carolina 27601-1029, USA \\ ${ }^{4} \mathrm{CIBIO} / \mathrm{InBIO}$, Centro de Investigação em Biodiversidade e Recursos Genéticos da Universidade do Porto, R. Padre Armando Quintas, 4485-661 Vairāo, Portugal; \\ National Institute of Ecology, 1210, Geumgang-ro, Maseo-myeon, Seocheon-gun, Chungcheongnam-do, 33657, Korea
}

bout $35 \%$ of snakes (685 of 1,935 species) are fossorial or Acryptozoic-fossorial species that spend much of their life hidden from human view underground or in leaf litter. One genus, Atractus Wagler 1828 (Dipsadidae) is the most diverse

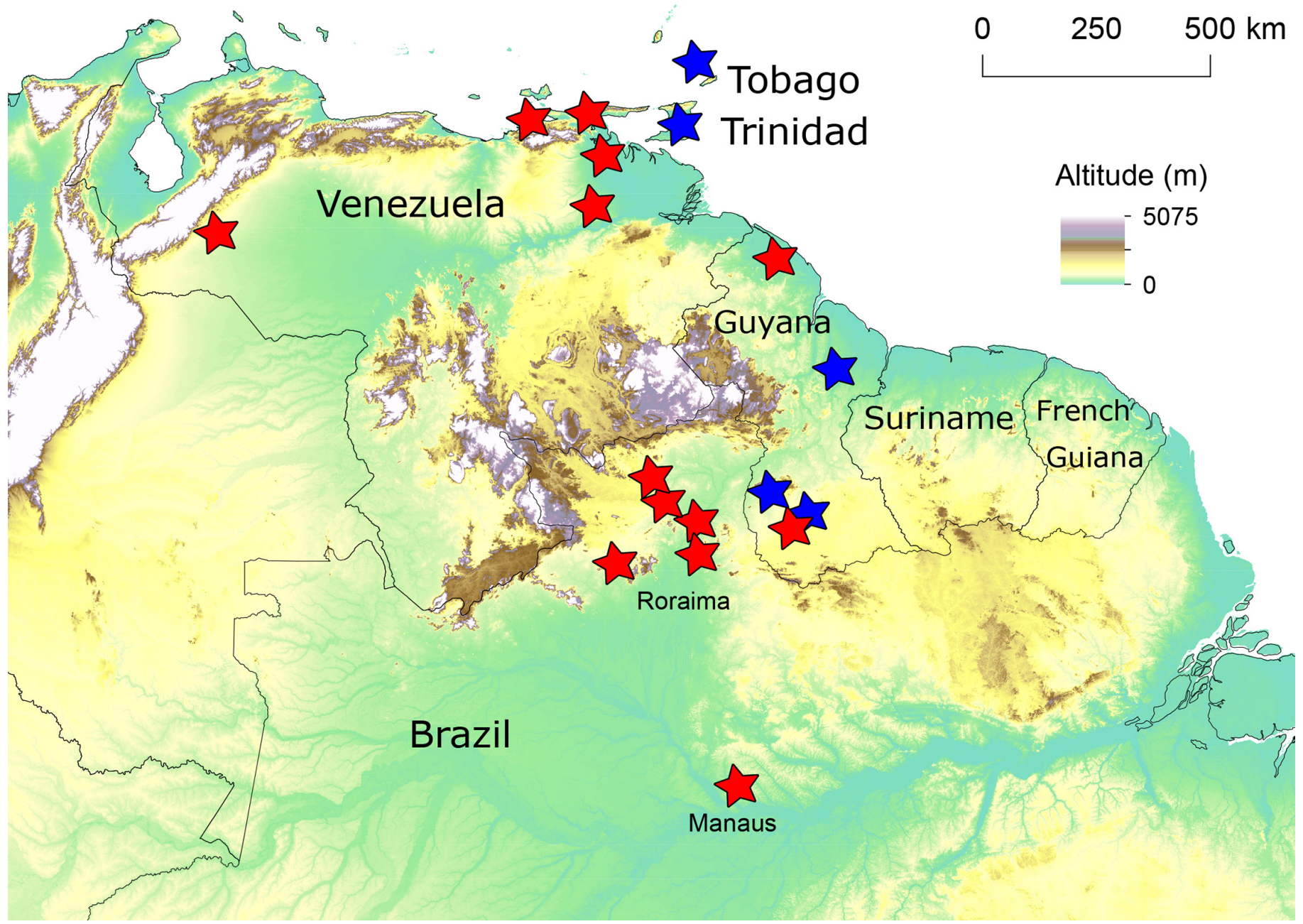

Fig. 1. Known localities for Three-lined Snakes (Atractus trilineatus) based on specimens examined and the literature. Blue stars are sequenced specimens from Murphy et al. (2019) and red stars are specimens examined and from the literature. 
تै

की

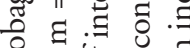

잉

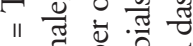

율 हैत

॥

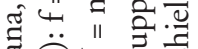

灾芯

$\circlearrowleft$ 凶舟当

它芯.

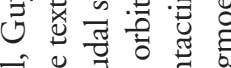

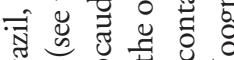

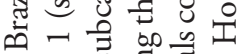

II

ส้

คี :

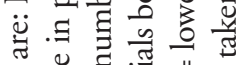

दे

- 웜

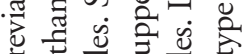

뉴 चु

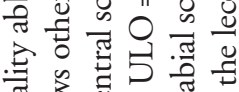

สู

光药

包

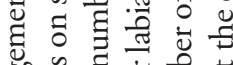

Б્ర

氹>合寻

" के

矛

$\dot{\alpha} \ddot{0}=0$

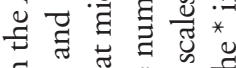

ஸ

ఫิ

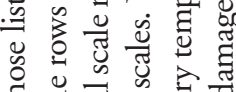

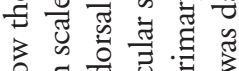

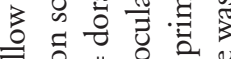

○

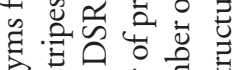

芯施吉

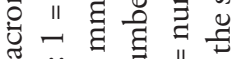

¿ $\ddot{\dot{u}} \Xi \Xi ّ$

寻卷元式

岁

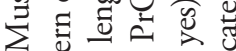

पं 䒕

‡॥

胥

踏

द ह छ

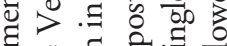

छ I

के त्र

후를을

ฐ

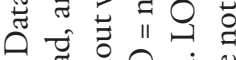

- .

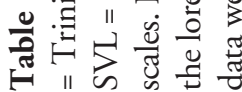

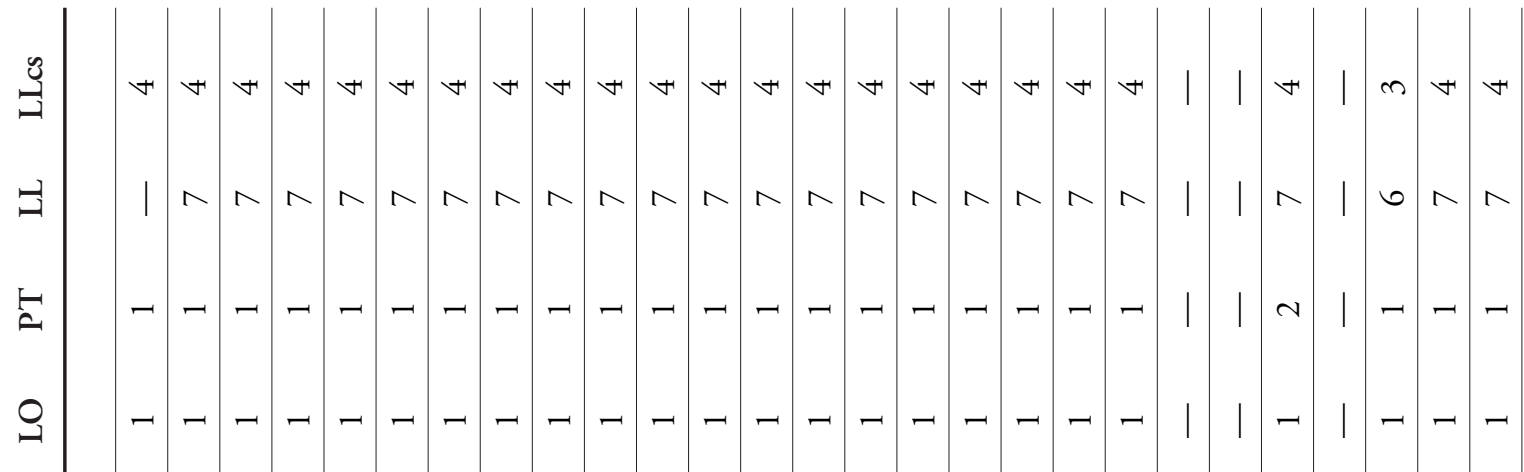

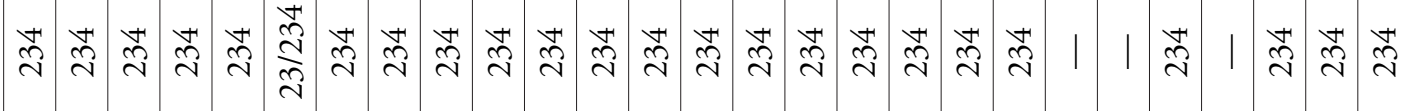

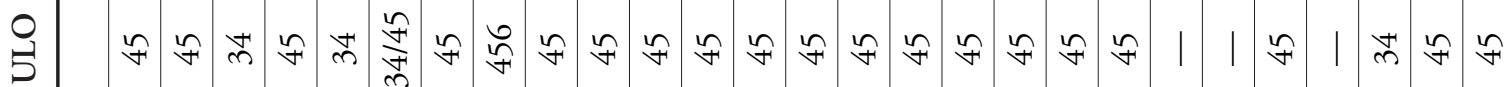

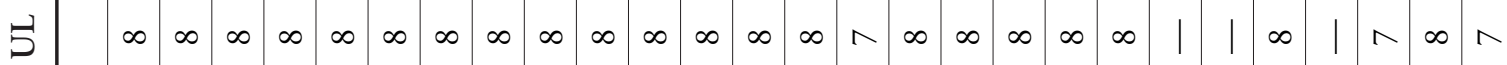

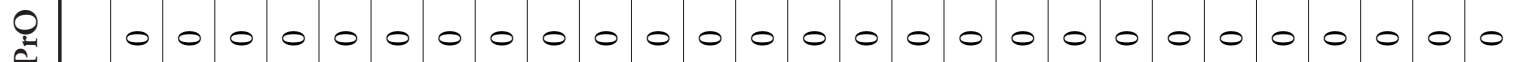

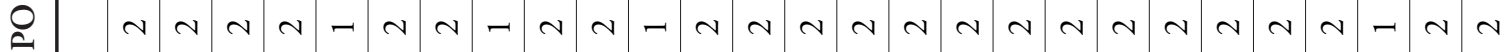
Z

แ

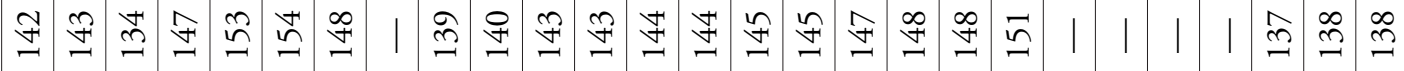

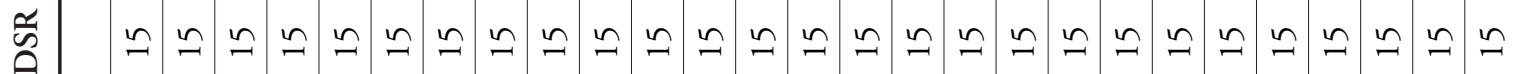

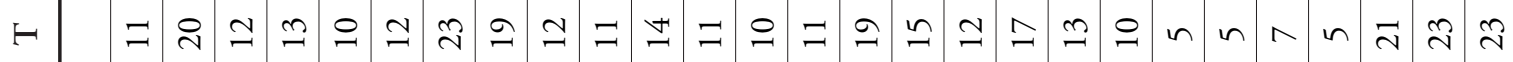

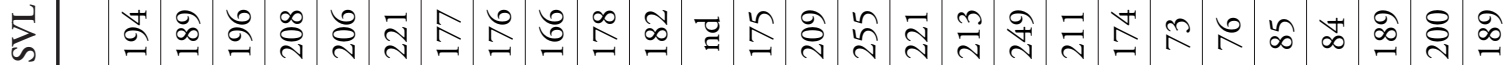
ш Ішшшш

昂 焉

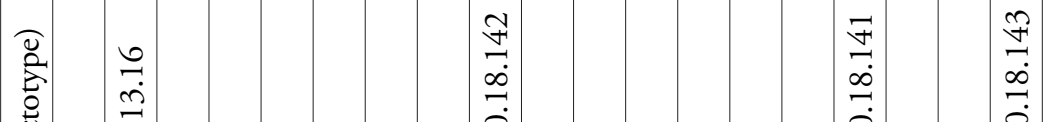

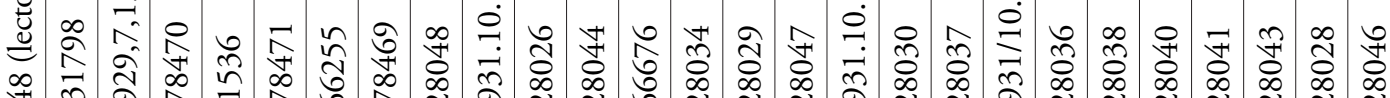

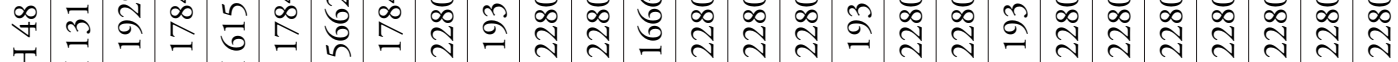

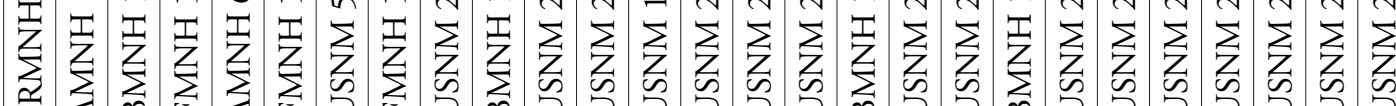




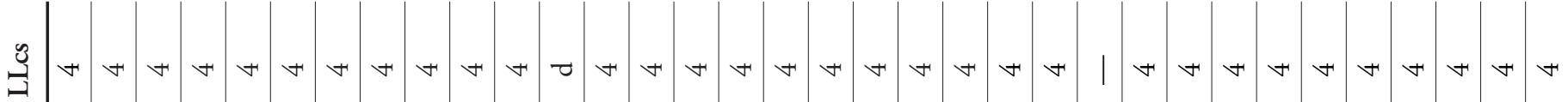

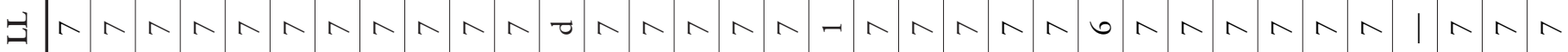
气

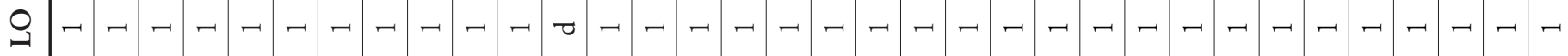
Э)

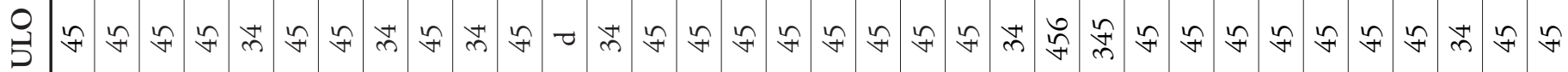

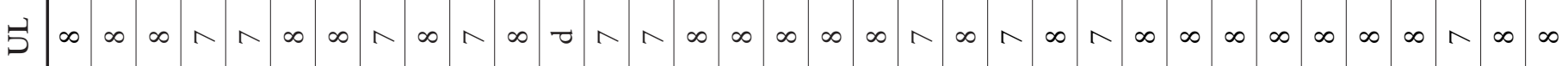
I

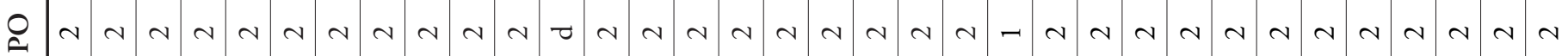

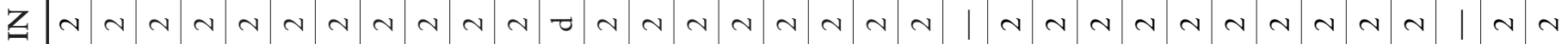

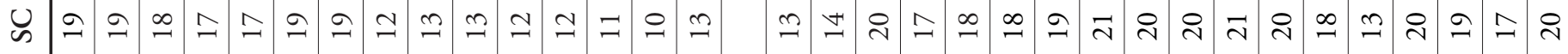

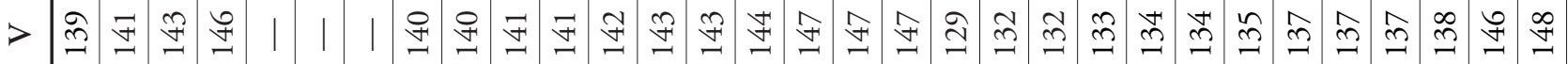

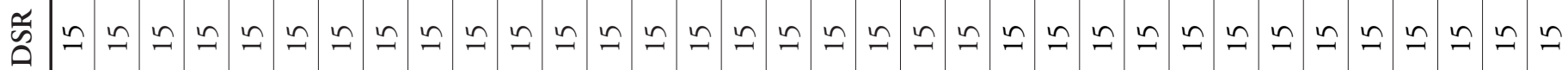

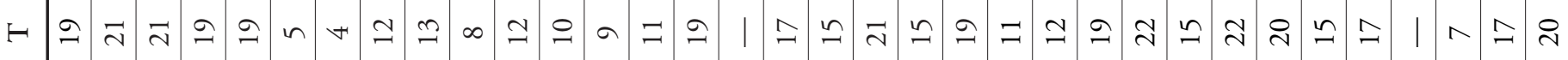

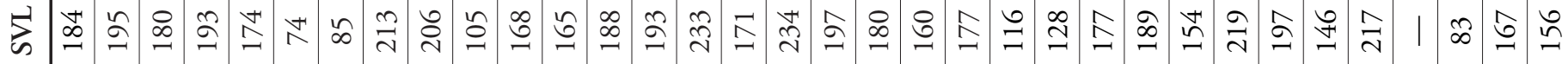

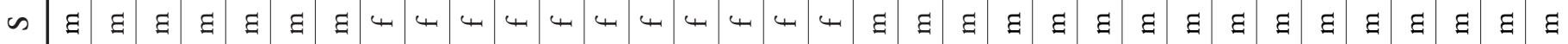

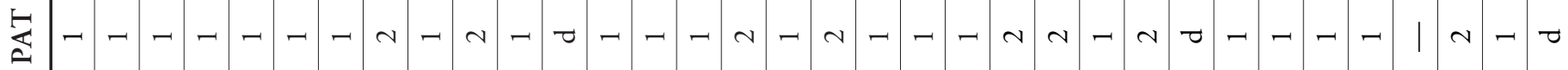
窇

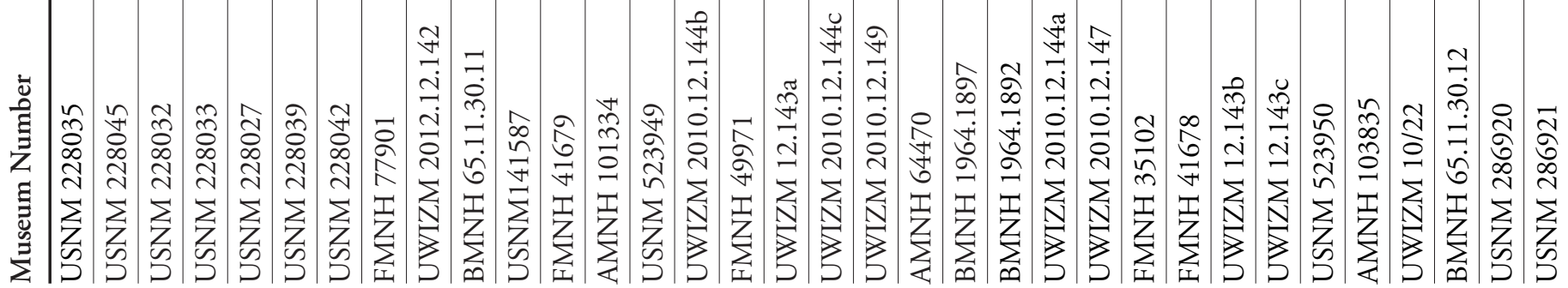




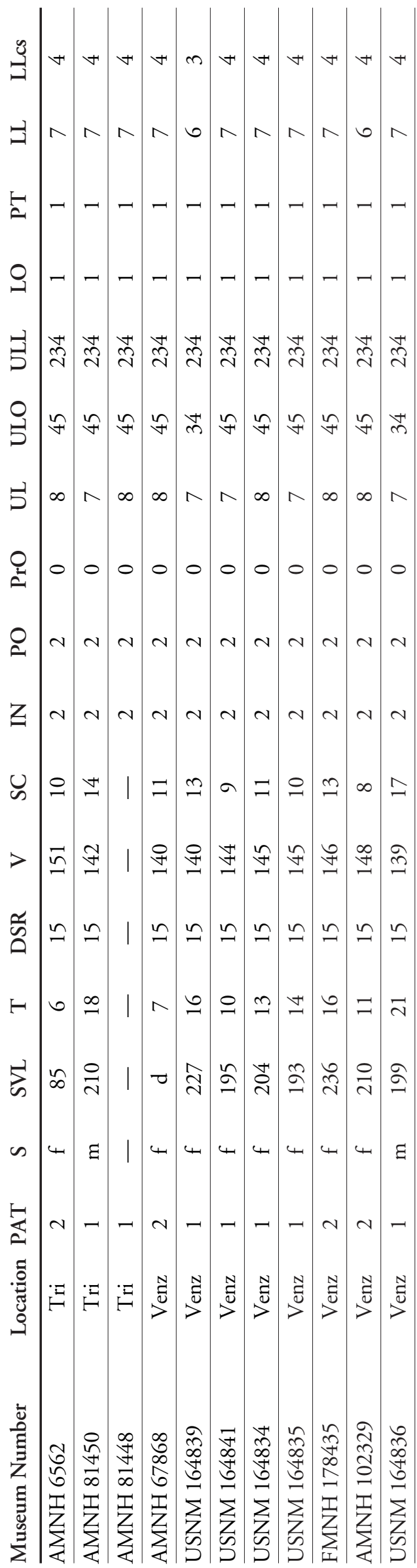

of extant snake lineages with 143 currently recognized species (Uetz et al. 2019). The genus is primarily South American with some minor representation in Panama (Myers 2003). A comprehensive revision of the genus is lacking, and the alpha taxonomy of the clade is in disarray due to some species being known only from the type material, misidentified specimens, and the extraordinarily large number of species descriptions (Passos and Lynch 2010; Passos et al. 2019). Some of these are microendemics and are known only from the holotype or a small series of specimens from restricted ranges (Passos et al. 2007), whereas others are relatively widespread (Wallach et al. 2014). The Three-lined Snake, Atractus trilineatus (Wagler 1828), is the type species for the genus.

The Three-lined Snake is found in Trinidad, Tobago, northern Venezuela, western Guyana, and in Brazil from Roraima as far south as Manaus. The origins of the Trinidad and Tobago populations and their relationships with mainland populations were investigated by Murphy et al. (2019). They found Atractus trilineatus to be deeply divergent from the other 31 congeners included in their analysis. Populations of $A$. trilineatus from Trinidad and Tobago show a close genetic affinity with mainland populations from Guyana, which suggests recent vicariance following Late Pleistocene sea-level rises, although overwater dispersal events cannot be ruled out, especially for the colonization of Tobago.

\section{Materials and Methods}

Terminology for Atractus head scalation follows Savage (1960) and ventral and subcaudal count methods follow Dowling (1951). We examined alcohol-preserved specimens from the herpetology collections at the American Museum of Natural History (AMNH), the British Museum of Natural History (NHM), the Field Museum of Natural History (FMNH), National Museum of Natural History (USNM), and the University of the West Indies Museum of Zoology (UWIZM). Specimens examined are listed in Table 1.

Sex was determined by tail shape, tail length, and visual inspection of the hemipenes. Dorsal scales were counted on the neck at about the 10th ventral, at midbody, and about 10 ventral scales anterior to the vent, and they were counted on the diagonal. Ventral counts, subcaudal counts, and tail/ SVL ratios were analyzed for sexual dimorphism. Scale counts and scale measurements were done under a dissection microscope. Scale measurements were taken with a metric ruler and dial calipers. Snake sizes are given in millimeters. Scale counts separated by a dash (-) represent a range taken from different individuals. Scale counts separated by a slash (/) represent data taken from a single individual in left/right order. A pattern formula of 45-8 signals a stripe on scale rows four and five and a second stripe on scale row eight.

Single factor ANOVAs, principal component analyses, and cluster analyses were performed in Excel with Xlstats and Data Lab with alpha $=0.05$. Means are presented \pm one stan- 
dard deviation. Hatchling measurements were taken before preservation. Individuals with body lengths less than $100 \mathrm{~mm}$ were assumed to be immature.

\section{Results}

Morphometric and meristic data for males and females from five populations of Atractus trilineatus are listed in Table 1 and comparisons are in Table 2. Females are longer, have shorter tails, lower tail/body length ratios, more ventrals, and fewer subcaudals than males. Sexual dimorphism in coloration is readily apparent in this species. Females tend to be red-tan or red-orange in color, whereas males are gray or gray-brown (Fig. 2). Sexual dimorphism data organized by the populations examined are in Table 1 and are graphed in Fig. 3.

The dorsal pattern can have stripes on scale rows 45-8 (common on Tobago and in Venezuela); 4-789 (in one Guyana specimen), 234-8, 2345-8 (common on Trinidad and in Venezuelan specimens), 34-678, 34-78, 345-8, or 45-78. Two postoculars usually are present, but a few specimens have just one. The tallest upper labial is usually the seventh, but it can be six, five, or eight; in six specimens the last upper labial is horizontally divided. Upper labials that contact the loreal are usually 234 but can be 23 or 345 . One primary temporal is typical, but two are sometimes present. Lower labials are usually seven, but some specimens have six; the first four usually contact the chin shields, but in one specimen only the first three contact the chin shields. The comparison of morphological traits in mainland and island populations suggests the species is morphologically variable as suggested by Garman (1887).

\section{Natural History}

On Trinidad and Tobago, Atractus trilineatus occurs in urban gardens, cocoa plantations, secondary forests, and primary forests (Emsley 1977; Mole 1924; Murphy 1997). Martins and Oliveira (1993) reported it from blackwater flooded forest in Brazil.

On Trinidad, we have found this species to be abundant in an experimental cacao plot on the campus of the University of the West Indies, as well as in the secondary forests of the Arima Valley and in some urbanized areas. Adults were found crossing roads at night; during the day they were collected by raking leaf litter and turning ground cover. We also have found specimens in clumps of leaf litter and debris that have been washed into roadside gutters and drains in both urban and forested areas.

The few stomachs we examined contained the remains of annelid setae. Mole (1924) reported that females lay 3-4 large eggs. In Trinidad, egg-laying has been reported for the months of March, April, and August, and eggs are about $18 \mathrm{x}$ $8 \mathrm{~mm}$ (Emsley 1977).

One of us (ALB) recovered 12 Atractus trilineatus eggs on Tobago from forest leaf litter and logs. On 15 December three eggs were removed from a rotting log on a forested slope behind Charlotteville (Table 3). These were maintained and transported to the United States, where they were kept at 20-22 ${ }^{\circ} \mathrm{C}$ until they hatched on 2-3 April (108 days later). Three eggs were recovered from a rotting log on 16 December; the log was shaded by a large tree and also contained a nest of ants. Two of the eggs were spoiled, the other contained a developing embryo. On 19 December, three eggs were found in vegetation debris and maintained for ten days in some of

Table 2. Morphometric measurements and meristic counts for Three-lined Snakes (Atractus trilineatus). Means are presented \pm one SD, ranges are in parentheses. $\mathrm{m}=$ males; $\mathrm{f}=$ females.

\begin{tabular}{lccccc} 
Population & SVL $(\mathbf{m m})$ & Tail $(\mathbf{m m})$ & Tail/SVL & Ventrals & Subcaudals \\
\hline Brazil $(\mathrm{m}, \mathrm{n}=1)$ & 189 & 20 & 0.11 & 143 & 19 \\
\hline Guyana $(\mathrm{f}, \mathrm{n}=5)$ & $207.17 \pm 19.0$ & $13.2 \pm 2.79$ & $0.06 \pm 0.01$ & $149 \pm 7.30$ & $12.83 \pm 0.69$ \\
\hline & $(196-239)$ & $(10-19)$ & $(0.06-0.08)$ & $(134-156)$ & $(12-14)$ \\
\hline Guyana $(\mathrm{m}, \mathrm{n}=1)$ & 176 & 19 & 0.11 & 148 & 21 \\
\hline Tobago $(\mathrm{f}, \mathrm{n}=13)$ & $204.92 \pm 25.57$ & $14 \pm 3.23$ & $0.07 \pm 0.01$ & $144.73 \pm 2.27$ & $12.69 \pm 1.73$ \\
\hline & $(166-249)$ & $(11-23)$ & $(0.05-0.10)$ & $(139-151)$ & $(10-16)$ \\
\hline Tobago $(\mathrm{m}, \mathrm{n}=8)$ & $188.0 \pm 7.87$ & $20.75 \pm 1.56$ & $0.11 \pm 0.01$ & $140.9 \pm 3.01$ & $18.75 \pm 1.79$ \\
\hline & $(174-200)$ & $(19-23)$ & $(0.10-0.12)$ & $(137-146)$ & $(17-21)$ \\
\hline Trinidad $(\mathrm{f}, \mathrm{n}=12)$ & $192.55 \pm 26.34$ & $12 \pm 3.69$ & $0.06 \pm 0.01$ & $143 \pm 2.58$ & $18.75 \pm 1.79$ \\
\hline & $(165-249)$ & $(10-17)$ & $(0.05-0.07)$ & $(140-147)$ & $(17-21)$ \\
\hline Trinidad $(\mathrm{m}, \mathrm{n}=8)$ & $195.72 \pm 16.56$ & $19.75 \pm 1.71$ & $0.10 \pm 0.01$ & $136.5 \pm 5.07$ & $12.09 \pm 1.24$ \\
\hline Venezuela $(\mathrm{f}, \mathrm{n}=6)$ & $(177-219)$ & $(17-22)$ & $(0.08-0.12)$ & $(129-146)$ & $(10-14)$ \\
\hline & $210.83 \pm 15.87$ & $13.11 \pm 2.29$ & $0.06 \pm 0.01$ & $144.6 \pm 2.34$ & $10.67 \pm 1.89$ \\
\hline Venezuela $(\mathrm{m}, \mathrm{n}=1)$ & $(195-227)$ & $(11-16)$ & $(0.05-0.07)$ & $(140-148)$ & $(8-13)$ \\
\hline
\end{tabular}



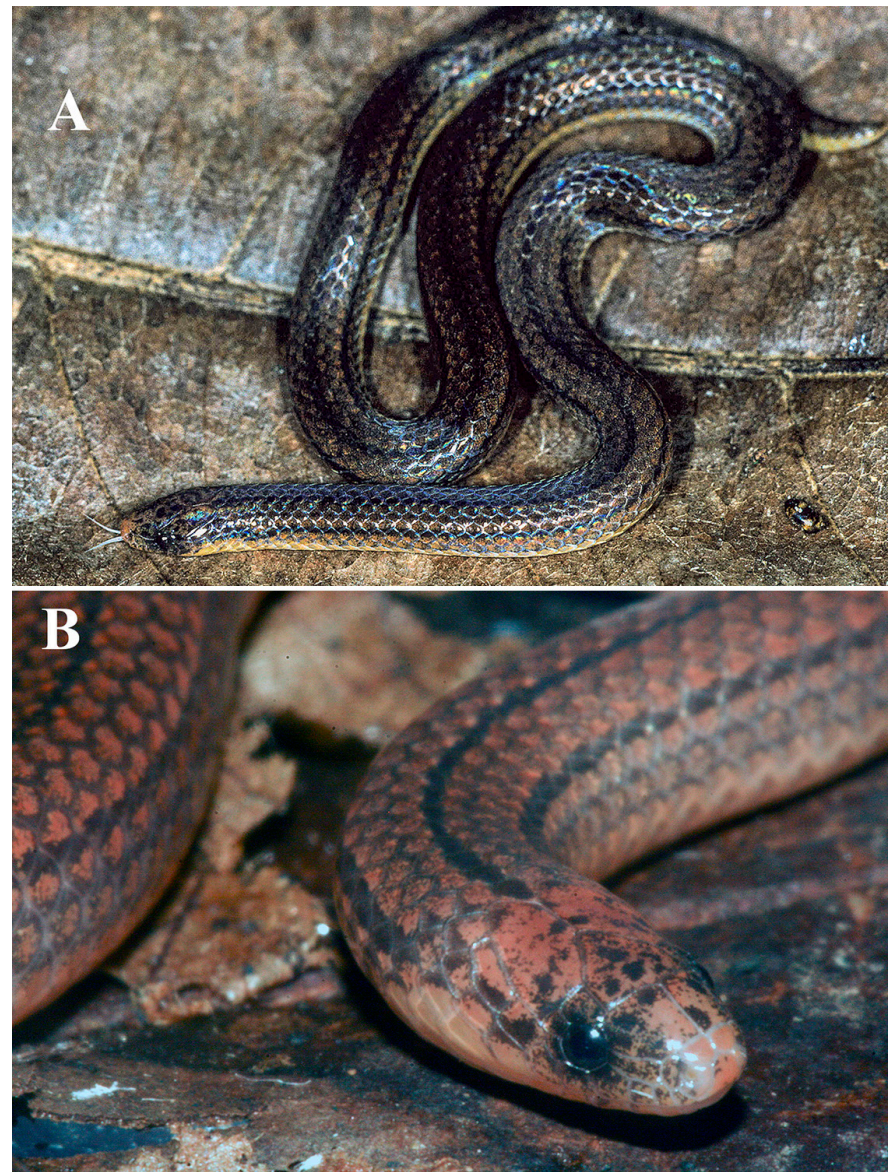

Fig. 2. Male (A) and female (B) Three-lined Snakes (Atractus trilineatus) from Trinidad. Males are gray-brown in colo, whereas females are redgray. Sexually dimorphic coloration is known from relatively few species of snakes. Photographs by John C. Murphy.

the debris. All hatched on 14 March (85 days later). A second clutch also found on 19 December contained two eggs found in forest leaf litter. On 26 December, one egg was taken from forest litter and maintained until it hatched on 14 February (50 days later). Six hatchlings were measured, total lengths ranged from $84-99 \mathrm{~mm}($ mean $=90.83 \pm 6.28 \mathrm{~mm})$. Tails were $5.0-9.5 \mathrm{~mm}$ (mean $=7.1 \pm 1.2 \mathrm{~mm}$ ). The mean female SVL from Tobago was $203.75 \mathrm{~mm}$. Thus, hatchlings average $44.5 \%$ of average female body length or $35.6 \%$ of the largest female measured in this study.

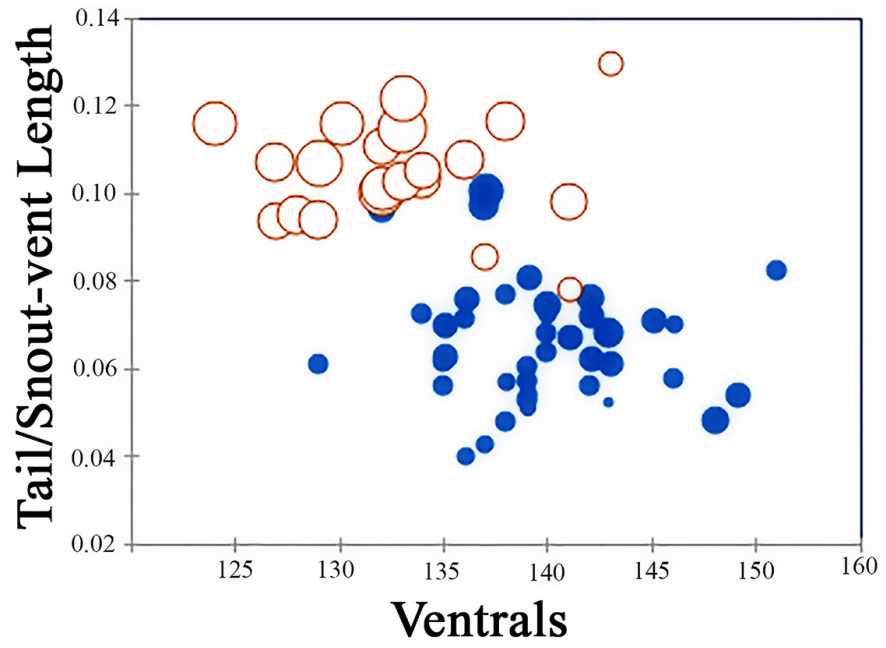

Fig. 3. Sexual dimorphism of tail-SVL ratios in Three-lined Snakes (Atractus trilineatus) plotted against ventral scale counts. Blue marks indicate females, brown marks males.

We have removed specimens of this snake from the stomachs of the Red Snake (Erythrolamprus ocellatus) and a coral snake (Micrurus circinalis).

\section{Discussion}

Phylogenetic analyses (Murphy et al. 2019) indicate Atractus trilineatus to be the sister lineage of the clade including all other Atractus species examined, although with a considerably high genetic divergence from its sisters. Atractus is an extremely diverse genus with 143 recognized species, of which the molecular analysis included only 31 (22.4\%). Therefore, as more species are added, the topology of the tree can be expected to change.

The island-mainland distribution of $A$. trilineatus is likely the result of sea level changes in the eastern Caribbean. Today the archipelago populations are isolated but were likely continuous with the mainland multiple times during the Pleistocene. Trinidad was connected to the mainland for longer periods than Tobago. The -410 Kya mean age of divergence reported by Murphy et al. (2019) between the Guyana and Trinidad and Tobago populations suggests that the island populations were isolated from the mainland during sea-level high stands and connected to South American at sea level low stands

Table 3. Data for five clutches of Three-lined Snake (Atractus trilineatus) eggs from Tobago.

\begin{tabular}{lcccc}
$\begin{array}{l}\text { Date } \\
\text { Collected }\end{array}$ & $\begin{array}{c}\text { Date } \\
\text { Hatched }\end{array}$ & $\begin{array}{c}\text { Days of } \\
\text { Incubation }\end{array}$ & $\begin{array}{c}\text { Incubation } \\
\text { Temperatures }\end{array}$ & $\begin{array}{c}\text { Clutch } \\
\text { Size }\end{array}$ \\
\hline 15 Dec & $2-3$ April & 108 & $20-22$ C & 3 \\
\hline $16 \mathrm{Dec}$ & none hatched & - & - & 3 \\
\hline $19 \mathrm{Dec}$ & 13 March & 85 & - & 3 \\
\hline $19 \mathrm{Dec}$ & none hatched & - & - & 2 \\
\hline $26 \mathrm{Dec}$ & $14 \mathrm{Feb}$ & 50 & - & 1 \\
\hline
\end{tabular}


(Fig. 4). The same explanation can be used for the isolation and divergence of Trinidad and Tobago populations, which according to Murphy et al. (2019) took place about 180 Kya.

Monsoon rains and associated flooding in northern Venezuela are known to form rafts of vegetation that wash up on the southern coastlines of Trinidad (Charles 2013). Murphy et al. (2019) presented two pieces of information that support the view that $A$. trilineatus is spending time in the water as unlikely as it may seem. Martins and Oliveira (1993) reported it from the black-water flooded forest in Brazil and Snyder (2016) found a specimen in the stomach of a Red-bellied Piranha (Pygocentrus nattereri) collected in flooded forest.

\section{Natural History, Dispersal, and Phylogeography}

Natural history provides additional insight into the phylogeography of Atractus trilineatus. A diet of earthworms and possibly insects (Mole 1924, this study), the elongated incubation time (a minimum of 108 days; see Table 3), yearround reproduction, placement of eggs in vegetative debris and logs, and the relatively large size of offspring all contribute to the ability of Atractus trilineatus to disperse via large rafts of floating vegetation. The relationships between natural history, biogeography, and phylogeography are frequently overlooked, which is a mistake - after all natural selection influences the distributions of lineages (Avise 2004).

\section{Acknowledgments}

Our sincerest thanks go to Alan Resetar at the Field Museum (FMNH); Bryan Stuart and Jeff Beane at the North Carolina Museum of Natural Science (NCSM); Frank Burbrink, Chris Raxworthy and David Kizirian at the American Museum of Natural History (AMNH); Colin McCarthy at the British Museum of Natural History (BMNH); Jens Vindum and Lauren Scheinberg at the California Academy of Sciences (CAS); Kevin de Queiroz and Jeremy F. Jacobs at the Smithsonian Institution (USNM); and Mike G. Rutherford at the University of the West Indies (UWIZM) for providing logistical support, access to the museums' collections, and the loan of specimens. All specimens were collected, euthanized, and preserved following guidelines detailed in the AISH pamphlet (Dupree 2004) and Institutional Animal Care and Use Committee guidelines (OLAW 2002). All collections were made under permits from The Wildlife Section of the Forestry Division, Ministry of Housing and the Environment; The Forestry Division, Trinidad \& Tobago, Ministry of the Environment and Water Resources, Trinidad \& Tobago; and the Department of Natural Resources and the Environment, Tobago House of Assembly. All state, federal, and international laws were followed for transporting live animals, preserved specimens, and tissues. No animals were obtained from animal dealers for this study. DS is currently supported by the program "Rita Levi Montalcini" (MIUR, Ministero dell'Istruzione dell'Università e della Ricerca) for the recruitment of young researchers at the University of L'Aquila.

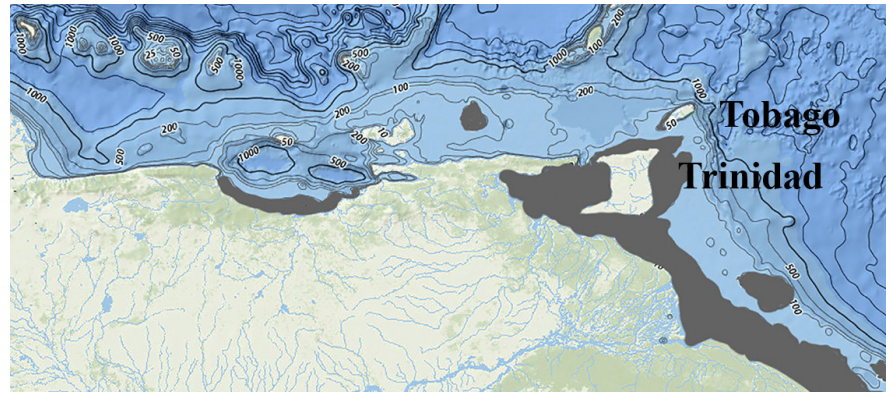

Fig. 4. The coastal plain of northern South America showing bathymetric contour lines. The area shaded in brown would have been exposed land when sea level dropped by $50 \mathrm{~m}$. The map is based on information found at https://maps.ngdc.noaa.gov/viewers/bathymetry.

\section{Literature Cited}

Avise, J.C. 2004. Molecular Markers, Natural History, and Evolution. 2nd ed. Sinauer Associates, Sunderland, Massachusetts.

Charles, S.C. 2013. An interesting reptile dispersal event from continental South America to Trinidad, Trinidad and Tobago. Living World, Journal of The Trinidad and Tobago Field Naturalists' Club 2013: 63.

Dowling, H.G. 1951. A proposed standard system of counting ventrals in snakes. British Journal of Herpetology 1: 97-99.

Duméril, A.M.C., G. Bibron, and A. Duméril. 1854. Erpétologie générale ou histoire naturelle complète des reptiles. Vol. 7. Roret, Paris.

Emsley, M.G. 1977. Snakes, and Trinidad and Tobago. Bulletin of the Maryland Herpetological Society 13: 201-304.

Garman, S. 1887. On West Indian reptiles in the Museum of Comparative Zoology at Cambridge, Mass. Proceedings of the American Philosophical Society 24: 278-286.

Martins, M. and M.E. Oliveira. 1993. The snakes of the genus Atractus Wagler (Reptilia: Squamata: Colubridae) from the Manaus region, central Amazonia, Brazil. Zoologische Mededelingen 67: 21-40.

Martins, M. and M.E. Oliveira. 1998. Natural history of snakes in forests of the Manaus region, Central Amazonia, Brazil. Herpetological Natural History 6: 78-150.

Mole, R.R. 1924. The Trinidad Snakes. Proceedings of the Zoological Society of London 94: 235-278.

Murphy, J.C., D. Salvi, A.L. Braswell, and M.J. Jowers. 2019. Phylogenetic position and biogeography of Three-Lined Snakes (Atractus trilineatus: Squamata, Dipsadidae) in the Eastern Caribbean. Herpetologica 75: 247-253.

Myers, C.W. 2003. Rare snakes - five new species from eastern Panama: Reviews of northern Atractus and southern Geophis (Colubridae: Dipsadinae). American Museum Novitates (3391): 1-47.

OLAW (Office of Laboratory Animal Welfare). 2002. Institutional Animal Care and Use Committee Guidebook, 2nd edition. National Institutes of Health, Bethesda, Maryland, USA.

Passos, P., D.S. Fernandes, and D.M. Borges-Nojosa. 2007. A new species of Atractus (Serpentes: Dipsadinae) from a relictual forest in northeastern Brazil. Copeia 2007: 788-797.

Passos, P., R. Fernandes, and N.A. Zanella. 2005. A new species of Atractus (Serpentes: Colubridae) from southern Brazil. Herpetologica 61: 209-218.

Passos, P. and J.D. Lynch 2010. Revision of Atractus (Serpentes: Dipsadidae) from middle and upper Magdalena drainage of Colombia. Herpetological Monographs 24: 149-173.

Passos, P., A. Scanferla, P.R. Melo-Sampaio, J. Brito, and A. Almendariz. 2019. A giant on the ground: Another large-bodied Atractus (Serpentes: Dipsadinae) from Ecuadorian Andes, with comments on the dietary specializations of the goo-eaters snakes. Anais da Academia Brasileira de Ciências 19: e20170976.

Savage, J.M. 1960. A revision of the Ecuadorian snakes of the colubrid genus Atractus. Miscellaneous Publications, Museum of Zoology, University of Michigan (112): 1-86.

Snyder, A. 2016. Atractus trilineatus (Three-lined Ground Snake). Predation. Herpetological Review 47: 308.

Uetz, P., P. Freed, and J. Hošek (eds.). 2019. The Reptile Database. <http://www. reptile-database.org>. 
Wagler, J. 1828. Auszüge aus seinem Systema Amphibiorum. Isis von Oken 21: $740-744$.
Wallach, V., K.L. Williams, and J. Boundy. 2014. Snakes of the World: A Catalogue of Living and Extinct Species. CRC Press, Boca Raton, Florida. 